\title{
TRINIDAD, HET GROOTSTE EN SCHOONSTE DER KLEINE ANTILLEN
}

\author{
DOOR

\section{K. KESLER}

Het is wel merkwaardig, dat dit grootste en schoonste eiland der Kleine Antillen zulk een betrekkelijk rustige geschiedenis gehad heeft. Terwijl om andere eilanden, als Martinique en het ten N.O. van Trinidad gelegen Tobago ${ }^{1}$ ) herhaaldelijk heftig is gestreden, is dat met dit eiland in veel geringere mate het geval geweest. En eveneens is het eenigszins opmerkelijk, dat het zoo lang geduurd heeft, eer een Europeesche mogendheid - in dit geval Engeland - het belang van het eiland ging inzien en het op moderne wijze ging exploiteeren. Dit geschiedde eerst in de 19e eeuw; voordien was het eiland een Spaansche bezitting, van gering belang voor het moederland.

1) Tobago is in dit tijdschrift en elders herhaaldelijk ter sprake gekomen. Zie o.a.: „Tobago, een vergeten Nederlandsche kolonie" door J. H. J. Hamelberg in het $4 \mathrm{e}$ Jaarverslag van het Geschied- Aardrijksen Oudheidkundig Genootschap van Curaçao (Amsterdam, J. H. de Bussy, 1900); W. I. G. jaarg. 1928, blz. 527 en vooral W. I. G., jaarg. 1939 en 1940, waarin de heer W. R. Menkman de geschiedenis van het eiland uitvoerig behandelt en verschillende onjuistheden en onvolledigheden van vroegere schrijvers verbetert of aanvult.

Tobago, dat voordien eenigszins onafhankelijk was, werd omstreeks de afschaffing der slavernij in de Britsche koloniën, in 1833, ingedeeld in de groep der ,"Windward Islands", die van Barbados uit bestuurd werden. Dit stelsel werd in 1876 losgelaten; toen verkregen Trinidad en Tobago ieder een eigen bestuur. In 1899 werd Tobago een onderhoorigheid van Trinidad. Dit werd vastgesteld bij K. B. van 20 October 1898, welk besluit bij Proclamatie van den Gouverneur van Trinidad d.d. 8 December 1898 ter algemeene kennis gebracht werd met bepaling, dat het in werking zou treden op 1 Januari 1899.

De beide eilanden worden thans bestuurd door een Gouverneur, bijgestaan door een Raad van vijf leden, de uitvoerende macht. Daarnaast staat een Wetgevende Vergadering, bestaande uit den Gouverneur, 11 ambtelijke, 6 niet-ambtelijke en 7 verkozen leden.

$$
-257-
$$

West-Indische Gids XXIII 
Volgens berichten werd Trinidad door Columbus tijdens zijn derde reis naar de West op 31 Juli 1498 ontdekt. Een eenvoudig gedenkteeken houdt dit feit op het eiland in de herinnering. Achter de kathedraal te Port of Spain, de hoofdstad, aan het einde van de Marine Square begint de Columbus Square. Hier staat een fontein met een standbeeld van den ontdekker, opgericht in 1881, met dit opschrift:

\section{CRISTOFERO COLOMBO, \\ Discoverer of the Island, 31 $1^{\text {st }}$ July 1498.}

Tusschen de Orinoco-delta en het eiland doorvarende, kwam het Spaansche eskader door de Boca de la Sierpe of de la Serpiente (slangenmuil) in de Golf van Paria. Het eerst kwamen in het gezicht drie heuveltoppen in het tegenwoordige district Moruga, thans "The three Sisters" genaamd. Daarna kwam men voor anker in de nabijheid van een landpunt, die Columbus „La Galera" noemde en die tegenwoordig bekend is als kaap Galeote. De drie, eerstgeziene, heuvels deden den ontdekker den naam Trinidad (Drieëenheid) aan de hand, die het eiland tot heden behouden heeft.

Columbus vertoefde daar slechts kort, dreef eenigen ruilhandel met de Indianen en verliet daarna de golf van Paria in het $\mathrm{N}$. door een der Bocas del Dragon (drakenmuilen) ${ }^{1}$ ), de vaarwaters tusschen Trinidad en Venezuela. Na dit korte bezoek van den grooten ontdekker duurde het nog geruimen tijd, eer Spanje het eiland definitief in bezit nam. Dit geschiedde in 1532; Trinidad kwam toen onder het bestuur van den eersten Spaanschen gouverneur Don Antonio Sedeño. Veel lieten de Spanjaarden zich echter niet aan de Kleine Antillen en ook niet aan dit eiland gelegen liggen en het duurde nog bijna een halve eeuw, eer er een vestiging van eenig belang op Trinidad plaats had, waardoor er een soort van hoofdplaats ontstond. Dat was het stadje San José

1) Tusschen het Venezolaansche schiereiland Paria en de N.-W. punt van Trinidad zijn verschillende doorvaarten (boca's) tusschen. de daar liggende eilandjes. Deze doorvaarten dragen de volgende namen: Boca Grande, tusschen Paria en het eiland Chacachacara; Boca de Navios (vaartuigen) tusschen Chacachacara en Huevos; Boca de Huevos tusschen het eilandje Huevos (eieren) en Monos en Boca de Monos (apen) tusschen het laatstgenoemde eiland en Trinidad.

Deze eilandjes zijn geliefkoosde uitspanningsplaatsen voor de bewoners van Port of Spain, de hoofdstad van Trinidad. 
de Orduña, gesticht tusschen de jaren 1577 en 1589 op de plaats, waar thans Saint Joseph (ten O. van Port of Spain) ligt.

De nabijheid van de Orinoco en de toegang, die deze rivier al spoedig verondersteld werd te geven tot het goudland van ,El Dorado" met zijn wonderbaar rijke stad Manoa op een eiland in het Parima-meer lokte intusschen nog vóór het einde der eeuw allerlei gelukzoekers van andere nationaliteit dan de Spaansche aan, begeerig in het wonderland fabelachtige schatten te verwerven.

Daardoor had het stadje San José de Orduña slechts een kortstondig bestaan, nl. slechts tot 1594, toen het door Engelschen uitgeplunderd en geheel verwoest werd. Dit waren manschappen van schepen, die onder bevel van Sir Walter Raleigh van Plymouth uitgezeild, op weg naar „El Dorado” op 22 Maart bij La Brea aan de Z.W.-kust van Trinidad het anker lieten vallen. Reeds het jaar te voren waren er Engelsche vrijbuiters in de buurt geweest, wat den toenmaligen gouverneur van Trinidad, Don Antonio de Berreo, aanleiding gegeven had, om hulptroepen uit het moederland te verzoeken. Daar werd dan ook een expeditie-corps uitgerust, dat in het laatst van het jaar van San Lucar naar Venezuela uitzeilde met opdracht, de Spaansche vestigingen aan de Orinoco te beveiligen. De boven genoemde Britsche vrijbuiters keerden echter zonder veel voordeel behaald te hebben, na korten tijd naar Engeland terug.

Het waren een paar schepen onder bevel van Jacob Whiddon, een onderhoorige van Raleigh, die door dezen vooruitgezonden waren, om „El Dorado” op te zoeken, daar zijn vrouw ${ }^{1}$ ) zich er

1) Zij was Elisabeth, dochter van Sir Nicholas Throgmorton en gedurende eenigen tijd hofdame van koningin Elizabeth. Raleigh was kort te voren in het geheim met haar gehuwd. Toen de koningin op de hoogte kwam van de betrekkingen tusschen Raleigh en haar hofdame, liet de jaloersche, oude vorstin, die zulke amourettes van haar gunstelingen niet duldde, beiden in den Tower opsluiten. Kort daarna werden zij echter losgelaten, daar de diensten van Raleigh noodig waren, om er toezicht op te houden, dat van de kostbare lading van het, bij de Azoren buitgemaakte, Spaansche schip „,Madre de Dios” niet al te veel ontvreemd werd. Dit schip was in Dartmouth binnen gebracht. Een commissie, bestaande uit Raleigh, Drake en Cecil kreeg nu opdracht, zich daarheen te begeven, toezicht te houden op de lossing en zorg te dragen voor een juiste verdeeling van de buit. Deze laatste stemde de koningin, die behalve jaloersch ook niet weinig inhalig was, weder gunstig ten opzichte van haar vroegeren gunsteling; het haar toegewezen aandeel toch van de buit, die $£ 150.000$ waard bleek te zijn, was wel het leeuwendeel daarvan, ofschoon zij slechts twee scheep- 
aanvankelijk met kracht tegen verzette, dat hijzelf het bevel over deze avontuurlijke expeditie op zich nam. Het volgende jaar echter was het hem gelukt, de bezwaren van zijn vrouw te overwinnen en zeilde hij uit, om te trachten, zelf het begeerde doel te bereiken. Trinidad werd eerst veroverd en de gouverneur De Berreo gevangen genomen.

Raleigh ging met zijn krijgsgevangene vrij vriendschappelijk om en wist van hem verschillende gegevens omtrent „El Dorado" te verkrijgen. Deze toonde hem o.a. een afschrift van een officieel verhoor, afgenomen aan zekeren Juan Martinez, die medegedeeld had, dat hij door de Indianen aan de Orinoco gevangen genomen en zeven maanden in Manoa was vastgehouden, waar hij met eigen oogen de schatten gezien had. Dit verhaal, dat zoowel door Spanjaarden, als door Engelschen geloofd werd, versterkte bij de laatsten het vertrouwen, dat het hun zou gelukken, het Goudland te bereiken. Dit werd echter, noch toen, noch door latere tochten gevonden. Raleigh liet zijn schepen, die hij veronderstelde, niet op de rivier te kunnen gebruiken, bij Trinidad achter en beproefde met 100 man in vijf open booten zijn doel te bereiken. De sterke stroom maakte het echter na enkele dagen onmogelijk, daar verder tegenop te roeien en de expeditie keerde onverrichter zake naar Trinidad en vandaar naar Engeland terug, waar zij in Augustus aankwam. Van het verblijf voor Trinidad had men intusschen gebruik gemaakt, om de schepen voor de thuisreis in goeden staat te brengen en ze te kalefateren met asfalt uit het z.g. Pitch Lake ${ }^{1}$ ).

jes ter beschikking gesteld had. Raleigh zelf was minder tevreden, want hij kreeg slechts $£ 36.000$ toegewezen, waardoor hij aan de onderneming, die hij voor het grootste gedeelte zelf bekostigd had, slechts t 2000 verdiende.

1) Dit Pitch Lake, in het Spaansch „Tierra de la Brea” genaamd, (brea $=$ pek, teer; brear = teeren, breeuwen) is een uitgestrekte vlakte, waar door onderaardsche werking asfalt uit den bodem oprijst, dat, als het voldoende verhard is, in blokken weggevoerd wordt. Het ligt bij de Z.W.-kust ten W. van San Fernando.

Een Indiaansche overlevering verhaalt omtrent deze kale vlakte, dat daar in lang vervlogen tijden een weelderige plantengroei was, te midden waarvan een dorp van Indianen van den stam der Chaima's verscholen lag. Deze Indianen waren slechte menschen, die den toorn van den Grooten Geest opwekten door de kolibri's uit te roeien, de vogeltjes, waarin de zielen der afgestorvenen na hun aardsch bestaan een toevlucht vonden. Tot straf voor die euveldaad liet de Groote Geest het dorp met alle inwoners en de gansche omgeving in den grond verzinken en nimmer zou boom of struik op die plaats wassen. Zóó is de kale vlakte van het Pitch Lake ontstaan.

Behalve dit Pitch Lake zijn er nog eenige andere verschijnselen, die 
Raleigh's bezoek aan Trinidad was slechts een voorbijgaande episode, waarbij weliswaar belangrijke schade aan het eiland werd toegebracht, maar niet een blijvende vestiging van Engelschen daar beoogd werd. Dit was wel het geval in 1639, toen Warwick beproefde er een kolonie te stichten. Dit werd echter een mislukking, evenals een latere poging van denzelfden edelman, om in 1647 Tobago te koloniseeren.

Hoewel, wanneer zij eenmaal gevestigd waren, de verhouding der Britsche koloniën tot het moederland over het algemeen aanvankelijk niet onbevredigend was, hadden zij toch steeds met binnenlandsche moeilijkheden te kampen, ten gevolge waarvan er verschillende slechts een kort bestaan hadden en na enkele jaren door de kolonisten verlaten werden. Dat was ook met Warwick's kolonie op Trinidad het geval. De Britsche kolonisten stonden over het algemeen sterk op hun rechten en streefden er steeds naar, zooveel mogelijk hun eigen bestuurders te kiezen. Herhaaldelijk verneemt men de klachten, dat er uit het moederland maar gouverneurs gezonden werden, die moesten zien, wat zij van het nieuwe bezit konden maken; dat de belastingen te hoog en de overige kosten van het levensonderhoud te zwaar waren, waardoor Engelschen niet met Franschen en Hollanders, die in andere omstandigheden leefden, konden concurreeren. $\mathrm{Zij}$ waren uit het moederland vertrokken, om betere levensvoorwaarden te zoeken; bleken die niet bereikbaar, dan keerden zij liever naar hun oude omgeving terug. Deze gezindheid deed andere Britsche, in de West ondernomen, kolonisaties en ook die van Warwick mislukken.

Trinidad bleef verder Spaansch bezit tot het einde van de $18 \mathrm{e}$ eeuw. Gedurende tientallen van jaren bleef het niet veel meer dan een, vrijwel vergeten, uithoek van het overzeesche rijk, tot het tegen het einde der eeuw uit zijn langdurigen slaap scheen te ont-

op een eenigszins vulkanische gesteldheid van Trinidad wijzen. In het Oostelijk gedeelte van het eiland zijn eenige kleine slijk-vulkanen, die modder en kwalijk riekend water uitwerpen. Deze vulkanen werden in 1880 o.a. bezocht door de prinsen Albert Victor en George (den lateren koning George V), die toen een oefentocht met de „Bacchante” maakten.

Verder had op 4 November 1911 op eenigen afstand van het eiland in zee een uitbarsting plaats, waarbij zich kolommen rook en vuur vertoonden en waarna aan de oppervlakte een eiland van ong. 1 H.A. grootte verscheen. $\mathrm{Na}$ eenigen tijd liet de gouverneur hierop de Union Jack hijschen, om het voor Groot Brittannië in bezit te nemen. Het verzonk echter weder geleidelijk en was in Januari 1928 geheel onder den zeespiegel verdwenen. 
waken, om een bloeiender toekomst tegemoet te gaan. Nadat tot ongeveer 1740 groote armoede op het eiland geheerscht had, begon de toestand er langzamerhand te verbeteren, toen onder het bestuur van den laatsten Spaanschen gouverneur Don José Marìa Chacon een Franschman, Saint-Laurent, het initiatief nam tot het vestigen van verschillende nieuwe ondernemingen op het eiland. Met goed gevolg werd vooral sedert 1783 de vestiging van nieuwe kolonisten aangemoedigd, zoodat de bevolking in betrekkelijk korten tijd aanzienlijk vermeerderde. In het bovengenoemde jaar 1783 bedroeg deze nog niet meer dan ongeveer 300 zielen; in 1797 was zij vermeerderd tot 18.000 . In dien tijd ontstond ook San Fernando, thans de tweede stad van Trinidad. $Z$ ij werd in 1786 door Chacon gesticht en genoemd naar den zoon van koning Karel IV, den lateren Ferdinand VII (1814-1833).

Het Spaansche bewind dat ten slotte nog eenigen bloei aan Trinidad gebracht had, liep echter ten einde. De Fransche revolutie en de daaruit volgende oorlogen deden in sterke mate hun invloed ook in de West gevoelen en ook dit eiland bleef er niet voor gespaard. De strijd in West-Indië ging uiteraard hoofdzakelijk tusschen Engeland en Frankrijk en, dat het Spaansche Trinidad erin betrokken werd, was aan een, eigenlijk onbeteekenend, incident te wijten.

Eenige passagierende schepelingen van het voor Port of Spain liggende schip ,Alarm” waren op bezoek geweest bij een Britsche vrouw uit Wales, die in de Frederickstreet woonde. Op weg naar hun schip kwamen zij in botsing met Fransche kapers, die toevallig ook juist op het eiland waren. Eén der Britsche zeelieden werd door Franschen beleedigd, waarop een vechtpartij volgde. Officieren van het Britsche schip, die ook aan den wal waren, snelden hun kameraden te hulp en den volgenden dag liet de commandant, kapitein Vaughan, van het Britsche oorlogschip troepen aan land zetten. Het kwam toen niet tot een gevecht, maar wel was dit incident één der redenen voor de oorlogsverklaring, enkele maanden later van Spanje aan Engeland. Gedurende dien oorlog ging Trinidad voor goed voor Spanje verloren.

Op 12 Februari 1797 ging een Britsch eskader van het, drie jaar te voren op de Franschen veroverde, Martinique onder commando van admiraal Harvey en met een legercorps onder bevel van den generaal Sir Ralph Abercromby ${ }^{1}$ ) onder zeil, dat den

1) Sir Ralph Abercromby (1734-1801) was van Schotsche afkomst. $\mathrm{Na}$ een politieke en militaire carrière werd hij als kolonel op non-activiteit gesteld. Toen echter op 1 Februari 1793 de oorlog met Frankrijk 
21sten van dezelfde maand voor Trinidad aankwam. Een Spaansch eskader onder commando van den admiraal Apodaca lag bij Caspar Grande in de Chaguarama-baai. Dit deed echter niets voor de verdediging van het eiland; alleen liet de Spaansche admiraal zijn schepen in brand steken, om te beletten, dat zij in handen der Engelschen zouden vallen. Naar vermeld wordt, brak de brand het eerst uit op het admiraalsschip, een driedekker, waarvan de dekken geheel met zwavel en andere brandbare stoffen bestrooid waren ${ }^{1}$ ). Zonder de bescherming van de vloot

uitbrak, trad hij weder in actieven dienst en makte als generaal den, voor de Engelschen weinig succesvollen, veldtocht in de Zuidelijke Nederlanden in 1794 mede. Hierbij diende de latere Lord Wellington (destijds nog Arthur Wellesley) als luitenant-kolonel onder hem. Het Britsche leger was toen van weinig militaire waarde; de meeste officieren waren onbekwaam en hadden gewoonlijk hun positie aan protectie te danken. In 1795 keerde Abercromby naar Engeland terug en werd toen met 15.000 man naar de West gezonden met opdracht, de door de Franschen bezette eilanden te hernemen. Ondanks vertraging door een storm kwam het transport in het begin van 1796 op Jamaica aan, waarna achtereenvolgens St. Lucia, Demerara, St. Vincent en Grenada genomen werden. Op het eerstgenoemde eiland stelde Abercromby een zijner officieren, Sir John Moore, als gouverneur aan. Deze sneuvelde in 1809 tijdens den veldtocht in Spanje bij Coruña. Daar de Franschen onder Soult in de nabijheid waren, werd hij in alle haast op het slagveld begraven. Het bekende gedicht van den Rev. Charles Wolfe ,,The burial of the Soldier" herinnert hieraan. Het slotcouplet hiervan luidt:

Slowly and sadly we laid him down,

From the field of his fame fresh and gory;

We carved not a line, we raised not a stone,

But left him alone with his glory.

Abercromby zorgde in de West vooral voor goede verzorging en oefening van de manschappen en moedigde plichtsbetrachting der officieren door gepaste middelen zooveel mogelijk aan.

$\mathrm{Na}$ een kort verblijf in Engeland in den zomer van 1796 keerde hij naar de West terug, en bezette kort na zijn terugkeer Trinidad, waar hij den kolonel Picton als gouverneur achterliet. Een, ten slotte door de Engelschen ondernomen, aanslag op Portorico werd door het sterke garnizoen afgeslagen. Abercromby keerde toen wegens gezondheidsredenen naar Engeland terug. Na zijn herstel diende hij nog in Ierland en Schotland en commandeerde een legercorps bij de landing in 1799 in Noord-Holland, welke onderneming o.a. door den dapperen tegenstand van Daendels en de onvoldoende medewerking der Russen mislukte.

Abercromby werd vervolgens naar Egypte gezonden tegen het leger, dat daar door Bonaparte bij zijn vertrek in October 1799 was achtergelaten. Hier sneuvelde hij in een der gevechten.

1) Het schijnt niet ontwijfelbaar zeker te zijn, dat de brand op de 
aan zichzelf overgelaten, kon de Gouverneur Chacon niet veel anders doen, dan het eiland aan de Engelschen overgeven, waardoor de Spaansche heerschappij, die ruim $2 \frac{1}{2}$ eeuw geduurd had, voor goed een einde nam. Abercromby's adjudant, de kolonel Thomas Picton ${ }^{1}$ ) werd de eerste Britsche gouverneur van Trinidad.

Picton nam al spoedig doortastende maatregelen om het, onder zijn bestuur gestelde, eiland tot grooteren bloei te brengen, dan

Spaansche schepen opzettelijk was aangestoken; andere berichten spreken van een ongeluk. Vast staat echter wel, dat de brand het eerst op het admiraalsschip uitbrak. In ieder geval was het gevolg ervan, dat het Spaansche eskader niets kon doen voor de verdediging van het eiland.

1) Thomas Picton (1758-1815) diende in het Britsche leger tot den rang van kapitein. Hij werd toen op non-activiteit gesteld met de toezegging, binnen korten tijd in actieven dienst hersteld en tot majoor bevorderd te zullen worden. Deze belofte werd echter door het legerbestuur niet nagekomen, waarom Picton besloot, te trachten, bij de krijgsmacht in de West snellere promotie te verkrijgen, dan in het moederland voor hem mogelijk scheen. Hij grondde deze verwachting op bekendheid met Sir John Vaughan, destijds opperbevelhebber van de Britsche krijgsmacht in de West (dezelfde, die met Rodney aan de plundering van St. Eustatius had deelgenomen). Zijn verwachting werd niet teleurgesteld, daar Vaughan hem als zijn adjudant aanstelde, in welke functie hij gehandhaafd werd door Abercromby, die Vaughan na diens overlijden op Martinique in Augustus 1795 als commandant opvolgde. Met Abercromby nam Picton deel aan de verovering van St. Lucia, waarna hij tot luitenant-kolonel bevorderd werd en van St. Vincent, waarna hij den generaal naar Martinique en vandaar naar Engeland vergezelde. Met Abercromby in Januari 1797 in de West teruggekeerd, nam hij deel aan de expeditie naar Trinidad, waar hij, met zijn grondige kennis van het Spaansch als aanbeveling, tot gouverneur benoemd werd. Na zijn ontslag op 31 Mei 1803 begaf hij zich naar Barbados en nam van hier uit deel aan een expeditie tegen het, door de Franschen opnieuw bezette, St. Lucia, dat op 21 Juni, en aan een tegen Tobago, dat op 30 Juni 1803 in bezit genomen werd. Picton werd toen tijdelijk gouverneur van het laatste eiland, nadat het door den Franschen generaal Berthier was overgegeven. Na het proces in Engeland nam hij deel aan de expeditie van Lord Chatham naar Zeeland in 1809 en werd na de verovering van Vlissingen tot gouverneur van die stad benoemd. De beruchte Zeeuwsche koortsen, die het Britsche leger zoozeer teisterden, tastten ook zijn gezondheid aan, waarom hij naar Engeland moest terugkeeren. Na zijn herstel nam hij deel aan den veldtocht in Spanje en ten slotte aan dien in België. Hij sneuvelde in den slag bij Waterloo tijdens een Fransche cavaleriecharge. Door de zorg van een zijner adjudanten werd zijn lijk later naar Engeland overgebracht. In St.-Paul's Cathedral te Londen werd te zijner eer een monument opgericht. 
het onder Spaansch beheer bereikt had. Allereerst reorganiseerde hij het bestuur en bracht daarin verschillende verbeteringen aan. Verder handhaafde hij een strikte discipline onder het garnizoen, dat uit 500 man, waaronder 300 Britten, bestond en organiseerde een politie-corps, dat niet alleen in Port-of-Spain, de nieuwe hoofdstad, maar op het geheele eiland moest dienst doen. Hij zorgde voorts voor verbetering der bestaande en voor aanleg van nieuwe wegen en trachte de welvaart te bevorderen o.a. door den handel met de Spaansche nederzettingen aan den overwal aan te moedigen, ter bescherming waarvan hij in overleg met Harvey ${ }^{1}$ ) kleine vaartuigen beschikbaar stelde.

Door al deze maatregelen wist hij te bewerken, dat zes maanden na zijn aanvaarding van het bestuur op het geheele eiland volkomen rust heerschte. Toen dan ook de generaal Abercromby vóór zijn vertrek naar Engeland nog een bezoek aan Trinidad bracht, keurde hij de, door Picton genomen, maatregelen onvoorwaardelijk goed. Deze, vooral die, welke den door Spanje verboden handel met de koloniën in Zuid-Amerika betroffen, lokten echter tegen-maatregelen van Spaansche zijde uit. Om dien handel te beletten, lieten de gouverneurs aan de mondingen der rivieren versterkte bastions opwerpen en door die van Guiana en van $\mathrm{Ca}$ rácas werd een prijs van $\$ 20.000$ op het hoofd van den gouverneur van Trinidad gesteld. Toen Picton hiervan kennis kreeg, schreef hij den beiden gezaghebbers een ironischen brief, waarin hij er zich over beklaagde, dat zij hem slechts op dien prijs en niet hooger taxeerden. Erger was het, dat, opgestookt door Spaansche spionnen van den overwal een begin van opstand onder de kleurling-bewoners van het eiland ontdekt werd. Door doeltreffende maatregelen wist Picton deze oproerige beweging echter spoedig te onderdrukken.

Dat door de rustige inwoners het Britsche bestuur echter gewaardeerd werd, bleek o.a. hierdoor, dat, toen in 1801 teruggave van het eiland aan Spanje ter sprake kwam, een aanzienlijk gedeelte der bevolking zich daartegen verzette. En als persoonlijk bewijs van waardeering voor zijn bestuur kan wel gelden, dat, toen in de eerste maanden van 1803 bekend werd, dat de Gouverneur ontslag gevraagd had, door de inwoners van Trinidad een verzoekschrift tot de regeering gericht werd, om dat ontslag niet te verleenen, een verzoek, waaraan niet voldaan werd. Op 31

1) Sir Henry Harvey (1737-1810) was sedert April 1796 Commander in Chief van de Britsche Leeward Islands. 
Mei 1803 legde de eerste Britsche gouverneur van Trinidad het bestuur neer en werd in de volgende maand vervangen door den generaal Frederick Maitland.

Picton's ontslagaanvrage was door het volgende veroorzaakt. De Britsche minister van koloniën Lord Sidmouth wenschte een proef te nemen met een nieuw systeem van bestuur der WestIndische eilanden, nl. niet door gouverneurs, maar door een meerhoofdige commissie. Zulk een commissie werd in 1803 voor Trinidad benoemd, bestaande uit den kolonel William Fullarton ${ }^{1}$ ), den kapitein Samuel Hood ${ }^{2}$ ) en Picton als derde lid. Fullarton kwam het eerst op Trinidad aan en, ofschoon hij goed door Picton ontvangen werd, openbaarde zich al spoedig een heftige vijandschap tusschen de beide mannen, waardoor samenwerking weldra geheel onmogelijk werd. Toen ook Hood daarna aangekomen was, besloot Picton ontslag te vragen, dat hem op 31 Mei 1803 verleend werd.

Fullarton meende ernstige bedenkingen te moeten maken tegen de wijze, waarop Picton het bestuur gevoerd had, en beschuldigde dezen o.a. ervan, op grove wijze machtsmisbruik gepleegd te hebben en herhaaldelijk lijfstraffen te hebben doen toepassen. Zoo zou volgens hem een kleurling-meisje, Luisa Calderon, op wreede wijze mishandeld zijn. Toen dit laatste in Engeland bekend werd, verwekte het daar, waar zich juist in dien tijd onder den invloed van Wilberforce en anderen een sterke strooming openbaarde voor afschaffing der slavernij en een meer menschelijke behandeling der inheemsche bevolking, een heftige verontwaardiging. Picton werd openlijk voor een ,,bloody tyrant" uitgemaakt en werd na zijn terugkeer in het moederland in een proces verwikkeld, waarbij hij zich op 36 tegen hem ingebrachte punten van beschuldiging had te verdedigen. De zwaarste tenlastelegging was het geval van Luisa Calderon. Het bleek, dat deze kleurlinge, te zamen met den man, met wien zij leefde, dief-

\footnotetext{
1) William Fullarton (1754-1808) diende eerst in Indië en keerde vandaar met den rang van kolonel naar Engeland terug. Hier werd hij lid van het parlement en werd door Lord Sidmouth tot commissaris van Trinidad benoemd.

2) Samuel Hood (1762-1814) was een neef van den gelijknamigen Britschen zee-officier, die onder Rodney aan den slag bij Dominica deelnam en o.a. het Fransche schip „,Barfleur” tot overgave dwong.

Tot commissaris van Trinidad benoemd, vertrok hij daarheen in October 1802. Op 25 April 1804 nam hij met Sir Charles Green bezit van Suriname. Onder zijn commando werd o.a. de „Diamond Rock” bij Martinique genomen en $1 \frac{1}{2}$ jaar door de Britten bezet gehouden.
} 
stal gepleegd had. De man was daarvoor tot gevangenisstraf veroordeeld; de vrouw was gedurende eenigen tijd in het openbaar te pronk gesteld.

Picton voerde te zijner verdediging o.a. aan, dat hij zich strikt binnen de bepalingen van zijn instructie gehouden had. Deze had hem voorgeschreven, voorloopig het Spaansche recht, zoowel het civiele als het strafrecht, op Trinidad te handhaven. Het Spaansche strafrecht nu kende lijfstraffen en bovendien werden maatregelen, zooals in het geval-Calderon geschied was, ook nog zelfs in Engeland wel genomen. Het proces verwekte een heftige sensatie in Engeland, in het bijzonder in Londen, vooral nadat inmiddels Fullarton uit Trinidad was teruggekeerd. Spoedig begon toen het geschil een zeer persoonlijk karakter aan te nemen en ontaardde in een strijd tusschen de beide tegenstanders. Van weerszijden, maar vooral van de zijde van Fullarton, werd niets nagelaten om de openbare meening te beïnvloeden; o.a. werden op ruime schaal afbeeldingen van de te pronk gestelde Luisa Calderon verspreid. Het proces had een voor Picton ongunstigen afloop; de uitspraak op 24 Februari 1806 was een veroordeeling van zijn beleid. In hooger beroep werd hij echter volkomen gerehabiliteerd. Op 11 Juni 1808 werd hij van alle tegen hem ingebrachte beschuldigingen vrijgesproken en geheel in eere hersteld. Fullarton beleefde deze uitspraak niet; hij was kort vóór het einde van het proces overleden.

Nog eenmaal kwam de kwestie van de teruggave van Trinidad aan Spanje ter sprake en wel bij de onderhandelingen over den vrede van Amiens. Lord Cornwallis vertegenwoordigde daarbij Engeland, Jozef Bonaparte Frankrijk. Evenals dat bij vroegere vredesonderhandelingen geschied was, liet de Eerste Consul ook ditmaal de eischen stellen van de teruggave van de Kaap en van Trinidad. Wat dit laatste betreft, hierop was hij vooral gesteld, om een geschikt punt te hebben, vanwaar aan Spanje hulp verleend zou kunnen worden bij de moeilijkheden in zijn ZuidAmerikaansche koloniën, waar zich een bedenkelijke gisting begon te openbaren.

Toen echter weldra de verhouding tot Spanje minder vriendschappelijk werd, liet Bonaparte op raad van Talleyrand den eisch betreffende Trinidad vallen. Engeland bleef daardoor in het bezit van het eiland, wat bij het sluiten van den vrede van Amiens in 1802 officieel bevestigd werd.

En, in plaats van een steunpunt voor Spanje bij oproerige bewegingen in de Zuid-Amerikaansche koloniën, werd het eiland 
nu weldra een plaats, vanwaar deze begunstigd werden. Reeds in 1798 had de Britsche gouverneur van het eiland verklaard, dat opstandelingen in Zuid-Amerika konden verkrijgen ,,all the succour to be expected, be it with forces or with arms and ammunition".

Francisco de Miranda trachtte in 1806 van die gezindheid gebruik te maken, om Venezuela van de Spaansche heerschappij te bevrijden. Met instemming, althans met medeweten van Jefferson, den vierden president van de Vereenigde Staten, en van Madison, zijn opvolger en destijds staatssecretaris, bereidde hij zijn aanslag, hoofdzakelijk op hun grondgebied voor. Met een troep van 200 man, vooral in de Vereenigde Staten aangeworven, begaf hij zich vandaar naar Trinidad en beproefde een landing in Coro. Hij werd echter onvoldoende van Britsche zijde gesteund en ontving ook in Venezuela niet den bijstand, waarop hij gemeend had te mogen rekenen, waardoor zijn onderneming niet het door hem gewenschte gevolg had. In weerwil van de mislukking van dezen aanslag bleef echter in het vervolg Trinidad, gelijk ook andere eilanden aan de Zuid-Amerikaansche kust dat weldra werden, een geliefkoosd oord, vanwaar uit Venezuela uitgewekenen aanslagen beproefden op het, hun onwelgevallige, bestuur van hun vaderland ${ }^{\mathbf{1}}$ ).

Het eiland bereikte intusschen onder Britsch bestuur in de $19 \mathrm{e}$ en deze eeuw een bloei, dien het onder Spaansch bewind nooit gekend had, hoewel er ook, evenals dat elders in West-Indië het geval was, zich ten gevolge van de afschaffing van de slavernij, gedurende geruimen tijd groote moeilijkheden voordeden. De oorzaak daarvan wordt kort en krachtig uitgedrukt in de verklaring van den gouverneur van Trinidad Lord Harris, die den nieuwen toestand aldus karakteriseerde: ,A race has been freed, but a society has not been formed". Inderdaad, een oordeel, dat niet alleen op Trinidad, maar op meer West-Indische gebieden nog geruimen tijd van toepassing was.

L i t e r a t u u r. Sir Algernon Aspinall, The Pocket Guide to the West-Indies, Methuen \& Co Ltd. London, 1934. - Colonel R. H. Vetch het artikel Picton en H. Morse Stephens, het artikel Fullarton, beide in Dictionary of National Biography.

1) Miranda hield in 1806 ook eenigen tijd op Aruba verblijf, waar hij, zich als heer en meester gedroeg; zijn secretaris was een Engelschman, Nicholas Vansittard. (Zie het art. van Mr. B. de Gaay Fortman in de Indische Gids, Januari 1931). 